\title{
Impact of Union Budget on Bank Nifty
}

\author{
Rayasam Sri Teja* \\ Rayasam Sri Teja, Post Graduate Scholar, VIT Business School, Vandalur-Kelambakkam Road, Chennai, \\ Tamil Nadu, India
}

*Corresponding Author: Rayasam Sri Teja, Rayasam Sri Teja, Post Graduate Scholar, VIT Business School, Vandalur-Kelambakkam Road, Chennai, Tamil Nadu, India

\begin{abstract}
The union budget is said to be the most watched event in economic policy making in our country. The Government tries to design the union budget in such a way that, it helps the economy to move upwards. Casual empirical studies shows that stock markets tend to be influenced by the budget. The budget expectations tends to affect Bank Nifty due to trading on both pre and post budget. The Indian stock market is found to react strongly to new information due to lack of transparency of information leading to a less than efficient market. The present study attempts to study the causal relationship between budget announcements and stock prices. It also studies the volatility and the impact of pre and post budget to establish the efficiency of one of the sectorial indices of NSE, i.e., BANK NIFTY.
\end{abstract}

Keywords: union budget, Bank Nifty, Nifty, NSE, Stock market, India, Economy, Econometrics

\section{INTRODUCTION}

In the modern Indian environment, the stock market index is considered as the barometer of the economic health and prosperity of the country. This is mainly due to the improvement in the economic atmosphere of the country. Expenditure of companies goes up with the industry demand, leading to the rise in consumption of various types of goods and services. This mainly leads to the increase in the net profits for the particular companies and therefore, there will be a rise in the share prices with is reflected through the index. The government has abundant tools and policies for executing its overall mission of performing its role for the social and economic growth. For the implementation of these prices, it issues guidelines in the form of the budget for the country once in a year.

The Government tries to design the union budget in such a way that, it helps the economy to move upwards. Most of the country's economic health can be judged easily by its major stock indices. But, it may potentially lead to the markets up and down during that particular period. That is why, the investors have to keep an eye on the budget and its impact on the stock markets. The annual budget or union budget is one of such kind of an event, where it is passed in the house of the parliament, India commonly known as "Sansad". This usually happens in the month of February. The Budget is said to be the most powerful instrument in the hands of the Government of India, for managing the economic resources of the country.

\section{NEED OF THE STUDY}

Budget is one of the fixed economic factors, which occurs once every year, and spending it in to the different sectors will be enunciated by the budget. As, budget can significantly impacts the economy of the country, the investors in the equity market will wait for the budget announcement so that, they can take an informed decision to on how to invest in the market.

\section{OBJECTIVES OF THE STUdY}

The main objective of the study is to research upon the returns of BANK NIFTY and the effect of budget on the volatility of stock market from 2005-2015.

\section{REVIEW OF LITERATURE}

The Research Study is about the "Impact of Union Budget on Stock Market". Some research articles were considered to analyse the factors that influence the stock markets. Many authors gave their valuable opinions through their study and it will be easy to understand the need of the study. 
Santanu Dutta (2011) in his article, "A Statistical Analysis Of Daily NIFTY Returns, During 20012011", has collected secondary data from S\&P CNX NIFTY Index and used the variables like maximum daily returns, Minimum daily return, Average daily return, variance of daily returns, Skewness coefficient, P-value, Percentage of daily returns exceeding two percent, percentage of daily returns below two percent, to apply on the tools like paired sample t test and examined that the NSE has gradually evolved into a weak form efficient market in 2010-2011. NSE has been efficient even during the very year 2008-09, during which equity markets all over the world had suffered due to global economic recession.

Vadali.Sri Ram Datta, Yanamala.Sunil Kumar, Lenina, Indukuri Sarika, Allam. Venkata Swamy (2015) in their article, "A Study Of Budget Impact On Stock Market", have collected Secondary data from NSE and used the variables like Beta, Sharpe differential measure, co relation, Augmented dickey fuller test, Volatility, weighted average, NIFTY, GDP, market capital to apply on the tools like correlation, annova, paired sample t test and founded that there is a relationship between budget amount allocated, Nifty, GDP, and market capital. The volatility has been observed high during the budget speech time.

Chakrapani, Kannaiah, Malla Redddy (2011) in their article, "A Study On Indices At NSE", have collected Secondary data from NSE and BSE and used the variables like index prices of various Nifty indices to apply on the tools like excel computation and predicted that the performance of Bank Nifty is good in March. It started a bit slow but it raised to a top price of the month due to the impacts and success of the banking sectors.

Sakshi Saxena, Nirmit Rana (2014) in their article, "A Study On The Impact Of Announcement Of New Banking License Policy 2013 On The Share Prices Of Selected NFBC's", have collected Secondary data from various NFBC's and used the variables like avg. return, standard deviation, minimum return, max. Return, price pre announcement, price post announcement, percentage change in stock prices to apply on the tools like descriptive statistics and their study showed very negligible reaction on or before the announcement date. The results are supporting to the implications of efficient stock market in its semi-strong form. By and large, market is near to efficiency in its semistrong form. Abnormal returns around the announcement date are not significant.

Deepak, Bhavya. N (2014) in their article, "An Event Study Analysis Of Union Budget Announcement On Broad And Sectorial Indices Of Indian Stock Market", have collected secondary data from BSE, NSE and used the variables like Average returns, Standard deviation to apply on the tools like paired sample $\mathrm{T}$ test and observed that the markets are reacting very positively to the budget in expectations of major reforms to meet the growth of the economy, but, react generally negatively in the post-event period.

Andreia Dionisio, Rui Menezes, Diana Mendes, Jacinto Vidigal Da Silva (2005) in their article, "Analysis Of The Relationship Between Stock Market Prices And Macroeconomic And Financial Factors: A Linear Approach", have collected secondary data from PSM and used the variables like dividend yield, earnings price ratio, Consumer price index, price index of PSM, short term interest rate, long term interest rate, industrial production index, industrial production index, unemployment, oil prices to apply on the tools like linear regression and examined the empirical the random walk model of stock price behaviour. The model makes two basic assumptions, one is Successive price changes are independent and another is the price changes conform to some probability distribution.

Jun Yu (2002) in his article, "Forecasting Volatility in the New Zealand Stock Market", has collected Secondary data from New Zealand stock market and used the variables like root mean square error, mean absolute error to apply on the tools like $\mathrm{GARCH}, \mathrm{ARCH}$, descriptive statistics and examined the nine univariate models for forecasting stock market volatility. The model considered in this article is the SV model.

Aabha Singhvi (2014) in their article, "Impact Of Union Budget On NIFTY", have collected Secondary data from NSE and used the variables like Average returns, Pre budget trading period, post budget trading period, short term period, medium term period, long term period closing prices. To apply on the tools like paired sample $\mathrm{T}$ test and founded that there is no significant impact on nifty index. 
In the above articles, many of the authors have used secondary data like closing points of the indices, budget dates, etc. They have considered variables like Mean return, Standard deviation, Risk Ratio, closing prices, daily average returns, etc. They have followed the models like descriptive statistics, correlation, $\mathrm{ARCH}, \mathrm{GARCH}$ models, regression, paired $\mathrm{p}$ sample test, unit root test, $\mathrm{t}$ test, sign test, $\mathrm{F}$ test Wilcoxon signed rank test, Philips perron tests, Mincer-Zarnowitz regression etc.

\section{ANALYSIS}

The average rate of returns for the Bank Nifty is as follows:

Table4: Average returns of Bank Nifty

\begin{tabular}{|c|c|c|c|c|c|c|c|c|c|}
\hline Year & Date & $\begin{array}{l}\text { last 30 } \\
\text { days }\end{array}$ & $\begin{array}{l}\text { next } \\
\text { days }\end{array}$ & $30 \mid \begin{array}{l}\text { last } \\
\text { days }\end{array}$ & $15 \mid \begin{array}{l}\text { next } \\
\text { days }\end{array}$ & 15 last 7 days & next 7 days & last 3 days & next 3 days \\
\hline 2005 & $28-02-2005$ & 0.083 & 0.005 & 0.015 & 0.021 & 0.005 & 0.081 & -0.004 & 0.038 \\
\hline 2006 & $28-02-2006$ & -0.005 & -0.002 & 0.030 & 0.000 & -0.006 & 0.010 & 0.029 & 0.006 \\
\hline \begin{tabular}{|l|}
2007 \\
\end{tabular} & 28-02-2007 & -0.093 & 0.008 & -0.097 & 0.037 & -0.068 & -0.017 & -0.010 & -0.055 \\
\hline 2007 & $29-02-2008$ & -0.152 & -0.205 & -0.050 & -0.179 & -0.072 & -0.154 & 0.004 & -0.105 \\
\hline 2008 & 16-02-2009 & -0.100 & 0.052 & 0.074 & -0.133 & 0.075 & -0.075 & 0.010 & -0.028 \\
\hline 2009 & 06-07-2009 & 0.077 & 0.018 & 0.052 & 0.054 & 0.065 & -0.005 & 0.017 & -0.044 \\
\hline 2010 & $26-02-2010$ & -0.029 & 0.050 & 0.011 & 0.032 & 0.018 & 0.029 & 0.001 & 0.012 \\
\hline 2011 & 28-02-2011 & -0.002 & 0.094 & -0.001 & 0.009 & -0.050 & -0.013 & -0.022 & 0.007 \\
\hline 2012 & 16-03-2012 & 0.063 & 0.008 & -0.009 & 0.004 & 0.042 & -0.022 & -0.008 & 0.033 \\
\hline 2013 & $28-02-2013$ & -0.057 & -0.003 & -0.039 & -0.028 & -0.033 & 0.043 & -0.009 & 0.022 \\
\hline 2014 & $17-02-2014$ & -0.077 & 0.193 & -0.072 & 0.137 & -0.003 & 0.017 & -0.015 & -0.013 \\
\hline 2014 & $10-07-2014$ & -0.007 & 0.084 & -0.018 & 0.055 & -0.021 & 0.068 & -0.028 & 0.031 \\
\hline 2015 & $28-02-2015$ & $\mid-0.007$ & -0.067 & 0.002 & -0.085 & -0.010 & -0.045 & 0.018 & -0.020 \\
\hline
\end{tabular}

when we observe the $+30,-30$ days period, there occurred a positive return on post budget period during the years, 2006, 2007, 2008, 2010, 2011, 2013, 2014,2014.

When we see the $+15,-15$ days period, during the years, 2005, 2007, 2009, 2010, 2011, 2012, 2013, 2014,2014 , the returns are high for the post budget period.

When we consider data for $+7,-7$ days, during the year 2005, 2006, 2007, 2010, 2011, 2013, 2014, 2014 , the returns are high.

When we see the $+3,-3$ days data, during the years, 2010, 2011, 20212, 2013, 2014, 2014, 2015, The returns are positive for the post budget period.

The Volatility for the Bank Nifty is as follows:

Table5: The Volatility of Bank Nifty

\begin{tabular}{|l|l|l|l|l|l|l|l|l|l|l|}
\hline Year & Date & $\begin{array}{l}\text { last 30 } \\
\text { days }\end{array}$ & $\begin{array}{l}\text { next } \\
\text { days }\end{array}$ & $\begin{array}{l}\text { last 15 } \\
\text { days }\end{array}$ & $\begin{array}{l}\text { next 15 } \\
\text { days }\end{array}$ & $\begin{array}{l}\text { last } \\
\text { days }\end{array}$ & $\begin{array}{l}\text { next } \\
\text { days }\end{array}$ & $\begin{array}{l}\text { last } \\
\text { days }\end{array}$ & $\begin{array}{l}\text { next } \\
\text { days }\end{array}$ \\
\hline 2005 & $28-02-2005$ & 0.011 & 0.012 & 0.009 & 0.011 & 0.009 & 0.011 & 0.008 & 0.011 \\
\hline 2006 & $28-02-2006$ & 0.010 & 0.009 & 0.011 & 0.008 & 0.013 & 0.009 & 0.019 & 0.009 \\
\hline 2007 & $28-02-2007$ & 0.012 & 0.014 & 0.014 & 0.015 & 0.015 & 0.019 & 0.019 & 0.018 \\
\hline 2008 & $29-02-2008$ & 0.023 & 0.021 & 0.018 & 0.026 & 0.015 & 0.026 & 0.014 & 0.029 \\
\hline 2009 & $16-02-2009$ & 0.017 & 0.020 & 0.015 & 0.019 & 0.011 & 0.015 & 0.010 & 0.016 \\
\hline 2009 & $06-07-2009$ & 0.016 & 0.014 & 0.016 & 0.015 & 0.015 & 0.015 & 0.015 & 0.015 \\
\hline 2010 & $26-02-2010$ & 0.009 & 0.006 & 0.007 & 0.005 & 0.006 & 0.005 & 0.005 & 0.006 \\
\hline 2011 & $28-02-2011$ & 0.013 & 0.009 & 0.012 & 0.009 & 0.013 & 0.010 & 0.014 & 0.014 \\
\hline 2012 & $16-03-2012$ & 0.012 & 0.010 & 0.012 & 0.011 & 0.011 & 0.014 & 0.009 & 0.014 \\
\hline 2013 & $28-02-2013$ & 0.006 & 0.010 & 0.006 & 0.010 & 0.007 & 0.006 & 0.007 & 0.007 \\
\hline 2014 & $17-02-2014$ & 0.008 & 0.009 & 0.009 & 0.010 & 0.008 & 0.008 & 0.009 & 0.008 \\
\hline 2014 & $10-07-2014$ & 0.009 & 0.008 & 0.008 & 0.009 & 0.008 & 0.010 & 0.012 & 0.012 \\
\hline 2015 & $28-02-2015$ & 0.010 & 0.010 & 0.010 & 0.010 & 0.010 & 0.012 & 0.010 & 0.014 \\
\hline
\end{tabular}

When we observe the data for last 30 days and next 30 days, during the years, 2005, 2007, 2009, $2013,2014,2015$; there is an increase in the volatility in the post budget period

When we see the data for $+15,-15$ days, during the years 2005, 2007, 2009, 2010, 2013, 2014 (temporary budget), 2014, 2015, there exist a positive/ high volatility on post budget period. 
When we see the data for $+7,-7$ days, during the years, 2005, 2007, 2008, 2009(temporary), 2009, 2012, 2014(temporary), 2014, 2015, there is a high volatility on the post budget period.

When we compare $+3,-3$ days w.r.to the budget day, during the years, 2005, 2008, 2009 (temporary), $2009,2010,2011,2012,2013,2014,2015$; there exists a high volatility in the stock market.

The Pearson correlation for the Bank nifty is as follows:

Table6: Pearson correlation proximity matrix for Bank Nifty

Proximity Matrix

\begin{tabular}{|l|r|r|r|r|r|r|r|r|}
\hline & \multicolumn{7}{|c|}{ Correlation between Vectors of Values } \\
\cline { 2 - 8 } & last 30 days & next 30 days & last 15 days & next 15 days & last 7 days & next 7 days & last 3 days & next 3 days \\
\hline last 30 days & 1.000 & .210 & .461 & .441 & .464 & .574 & .055 & .626 \\
next 30 days & .210 & 1.000 & .021 & .775 & .302 & .605 & -.459 & .522 \\
last 15 days & .461 & .021 & 1.000 & -.236 & .763 & .021 & .532 & .227 \\
next 15 days & .441 & .775 & -.236 & 1.000 & .092 & .755 & -.408 & .472 \\
last 7 days & .464 & .302 & .763 & .092 & 1.000 & .119 & .375 & .265 \\
next 7 days & .574 & .605 & .021 & .755 & .119 & 1.000 & -.358 & .815 \\
last 3 days & .055 & -.459 & .532 & -.408 & .375 & -.358 & 1.000 \\
next 3 days & .626 & .522 & .227 & .472 & .265 & .815 & -.334 & 1.000 \\
\hline
\end{tabular}

This is a similarity matrix

From the Pearson correlation, we have found that the variables like "next 15 days and next 30 days", "last 7 days and last 15 days", "next 7 days and next 15 days", "next 3 days and next 7 days" are positively correlated having the significance value greater than 0.7

\section{CONCLuSion}

From the average returns table, we can say that during 2006, 2007, 2008, 2010, 2011, 2013 and 2014, there exists a positive return during the pre-budget and post budget period. From the volatility analysis, we can conclude that during 2005, 2007, 2009, 2013, 2014, and 2015; there is an increase in the volatility in the post budget period. So, from the above results, 7 cases out of 10 cases are showing that, there is a positive impact of union budget on Bank Nifty.

From the Pearson correlation, we have found that the variables like "next 15 days and next 30 days", "last 7 days and last 15 days", "next 7 days and next 15 days", "next 3 days and next 7 days" are positively correlated having the significance value greater than 0.7

\section{REFERENCES}

[1] Santanu Dutta (2011) “A Statistical Analysis of Daily Nifty Returns, During 2001-11”, International Journal of Research in Commerce, It \& Management, Volume No. 1(2011), Issue No. 4(September).

[2] Vadali.Sri Ram Datta, Yanamala.Sunil Kumar, Lenina. M, Indukuri Sarika, Allam. Venkata Swamy (2015) "A Study of Budget Impact on Stock Market", Indian Research Journal, Volume: Ii, Series: 1. Issue: January, 2015.

[3] Chakrapani. R, Kannaiah. P, Malla Redddy. G (2011) "A Study on Indices at NSE”, International Journal of Management \& Business Studies, Vol. 1, Issue 3, September 2011.

[4] Sakshi Saxena, Nirmit Rana (2014) "A Study on the Impact of Announcement of New Banking License Policy 2013 on the Share Prices of Selected NFBC", Management Insight, Vol. 10, No. 1; June 2014.

[5] Arindam Gupta And Debashis Kundu (2005) " A Study On The Impact Of Union Budgets On Stock Prices In India ", ICFAI Journal Of Applied Finance, Vol. 12, No. 10, 2006.

[6] Andreia Dionisio, Rui Menezes, Diana Mendes, Jacinto Vidigal Da Silva (2005) "Analysis of the Relationship between Stock Market Prices and Macroeconomic and Financial Factors: A Linear Approach", International Journal of Innovative Research \& Development, vol 3 Issue 12.

[7] Yu Hsing (2013) "Effects Of Fiscal Policy And Monetary Policy On The Stock Market In Poland “, Journal Of Economics, Volume 1, Issue 3, 2013 Pg.: 19-25.

[8] Thomas Chiang. C, Shuh-Chyi Doong (2001) " Empirical Analysis of Stock Returns and Volatility: Evidence from Seven Asian Stock Markets Based On TAR-GARCH Model ", Journal of Economics, Volume 1, Issue 3, 2013 Pg.: 19-25.

[9] Jyothi U, Suresh. K (2014) "Estimating Stock Market Volatility Using Non-Linear Models", Review of Quantitative Finance and Accounting, 17: 301-318, 2001. 
[10] Bordoloi. S and Shiv Shankar (2009) "Estimating Volatility in the Indian Stock Markets: Some Explorations", Journal of Business and Management, Volume 16, Issue 2. Ver. I (Feb. 2014), Pp. 62-65.

[11] Hussain Ali Bekhet1 \& Nor Salwati B Othman (2012) " Examining The Role Of Fiscal Policy In Malaysian Stock Market", Journal of Financial Markets, Volume 5 Issue: 1.

[12] Cedric Mbanga. L and Ali Darrat. F (2011) "Fiscal Policy and the U. S. Stock Market", International Business Research, Volume 17: 301-318, 2001.

[13] Philip Hans Franses And Dick Van Dijk (1996) "Forecasting Stock Market Volatility Using (Non-Linear) GARCH Models", Journal Of Forecasting, Vol. 15. Pp.: 229-235.

Citation: Rayasam Sri Teja. “ Impact of Union Budget on Bank Nifty" International Journal of Managerial Studies and Research (IJMSR), vol 7, no. 6, 2019, pp. 17-21. doi: http://dx.doi.org/10.20431/2349-0349. 0706002.

Copyright: (c) 2019 Authors. This is an open-access article distributed under the terms of the Creative Commons Attribution License, which permits unrestricted use, distribution, and reproduction in any medium, provided the original author and source are credited. 